\title{
The Effects of Cryogenic Treatment on the Corrosion of AISI D3 Steel
}

\author{
Ilyas Uygur ${ }^{a}$, Husnu Gerengi ${ }^{b *}$, Yusuf Arslan ${ }^{c}$, Mine Kurtay ${ }^{b}$ \\ ${ }^{a}$ Department of Mechanical Engineering, Faculty of Engineering, \\ Duzce University, 81620, Düzce, Turkey \\ ${ }^{b}$ Corrosion Research Laboratory, Kaynasli Vocational College, Düzce University, \\ 81900 Kaynasli, Düzce, Turkey \\ 'Düzce Vocational College, Düzce University, 81620, Düzce, Turkey
}

Received: November 11, 2014; Revised: April 24, 2015

It is well known that cryogenic treatment is used to improve the mechanical properties of a material. Consequently, the use of cryogenic treatment has grown beyond its successful application on tool steels. In this research, the effects of cryogenic treatment on the corrosion of AISI D3 steel in 3.5\% $\mathrm{NaCl}$ solution were examined by electrochemical impedance spectroscopy (EIS). The surface structure of the AISI D3 steel was examined by scanning electron microscopy (SEM) after the EIS investigations. Results clearly indicated that the pre-treatment of the steel was responsible for a significant effect on corrosion. The heat treatment process prior to the cryogenic treatment and the tempering process after were shown to decrease corrosion resistance.

Keywords: corrosion, cryogenic treatment, electrochemical impedance spectroscopy, AISI D3 steel

\section{Introduction}

Cryogenic treatment is a supplementary process for conventional heat treatment. Unlike mere surface treatments, it is an inexpensive one-time treatment that affects the core properties of the component. Research has shown that cryogenic treatment increases product life and, in most cases, provides additional qualities to the product, such as stress relief and dimensional stability ${ }^{1,2}$. According to previous studies in the literature, two metallurgical phenomena have been reported as the main reasons for using cryogenic treatment: (1) the elimination of retained austenite and (2) the initiation of nucleation sites for the subsequent precipitation of a large number of very fine carbide particles along with their uniform distribution ${ }^{3,4}$. Cryogenically treated samples have also shown a nearly $0 \%$ fraction of retained austenite. This means that cryogenic treatment results in the transformation of retained austenite to martensite, which in quenched samples can be as much as $25 \%$ in volume. Cryogenic treatment, if properly employed, can provide a significant improvement in both productivity and product quality, and thus, overall machining economy, even after covering the additional cost of the cryogenic treatment 5 .

The alloy AISI D3 is a high-carbon, high-chromium steel developed for various applications which require high resistance to wear, severe pressure and abrasion. These include punching, blanking, stamping, cold-forming dies, cold trimmer and burnishing dies or rolls, slitting cutters, etc. It is worthy to note that punches which are made of AISI D3-grade alloy tool steel contain primarily martensite and metal alloy carbides. Such grades are generally considered to maintain a good balance between wear and corrosion resistance together with dimensional stability.

*e-mail: husnugerengi@duzce.edu.tr
Corrosion is the continuous gradual destruction of a material due to a chemical reaction with its environment. Corrosion can cause factory shutdowns, waste of valuable resources, loss or contamination of products, reduction in efficiency, costly maintenance, and expensive overdesign. Numerous experimental studies have been carried out to investigate the effect of deep cryogenic heat treatment on the mechanical properties of tool steels; however, very little research has focused on the effect of deep cryogenic heat treatment on the corrosion response $e^{6-8}$. The results of the present study showed that, due to a more uniform carbide distribution in association with a higher carbide percentage, the corrosion behaviour of deep cryogenically treated samples had been enhanced. For longer holding durations (e.g., $48 \mathrm{~h}$ ), the corrosion resistance has been seen to improve as a result of the increase in the carbide percentage by $3 \%$ (vol.\%) and a more uniform carbide distribution ${ }^{9}$. In the case of most stainless steels, however, cryogenic treatment causes the formation of martensite, which can improve the mechanical properties, but, unfortunately, can also negate the good resistance to corrosion. In steels, martensite is more susceptible to corrosion than austenite. In the deformed samples of the present study, it was found that the precipitated intergranular carbides were always within the martensite or along the martensite lath boundaries. The rapid sensitisation of austenitic steel is due to the fact that chromium and carbon diffuse more rapidly in body-centred-tetragonal martensite than in face-centred-cubic austenite ${ }^{10}$; the corrosion pitting phenomenon tends to initiate from the inclusion-matrix interface and martensite-rich regions. Thus, the objective of this study was to investigate the influences of deep cryogenic treatment and tempering on the corrosion performance of AISI D3 tool steel punches used for blanking on AISI 304 austenitic stainless steel. 


\section{Material and Methods}

Electrochemical measurements were carried out in a three-electrode type cell with separate compartments for the reference electrode $(\mathrm{Ag} / \mathrm{AgCl})$, the counter $(\mathrm{Pt})$ and the working (AISI D3 steel) electrodes having an area of $0.5 \mathrm{~cm}^{2}$. The surfaces of the working electrode were prepared by grinding with 400-1800 grade abrasive paper, rinsing with distilled water and then degreasing with acetone. During the measurements, the solution was stirred with a magnetic stirrer (500 rot $/ \mathrm{min})$. The composition of AISI D3 steel is given in Table 1.

Four types of uncoated AISI D3 steel samples were used: conventionally heat treated, $24 \mathrm{~h}$ cryogenically treated, $36 \mathrm{~h}$ cryogenically treated and $36 \mathrm{~h}$ cryogenically treated and then $2 \mathrm{~h}$ tempered at $150{ }^{\circ} \mathrm{C}$. The cryogenic treatment for the AISI D3 samples was achieved by gradually lowering them from room temperature to $-145^{\circ} \mathrm{C}$ at the cooling rate of about $5{ }^{\circ} \mathrm{C} / \mathrm{min}$ and holding at this cryogenic temperature for $24 \mathrm{~h}$ or $36 \mathrm{~h}$, then gradually bringing them back to room temperature at the heating rate of $5^{\circ} \mathrm{C} / \mathrm{min}$. The scheme in Figure 1 shows the various treatments and treatment cycles applied to the samples. The tempering of the AISI D3 steel was performed in a muffle furnace with the capacity of $9 \mathrm{~kW}$, $380 \mathrm{~V}$ and $1200{ }^{\circ} \mathrm{C}$.

Table 1. Chemical composition of AISI D3 steel.

\begin{tabular}{lc}
\hline \multicolumn{1}{c}{ Element } & Amount (wt \%) \\
\hline Carbon & $2.0-2.3$ \\
Manganese & 0.6 \\
Silicon & 0.6 \\
Nickel & 0.30 \\
Chromium & $11.0-13.5$ \\
Sulphur & 0.03 \\
Phosphorus & 0.03 \\
Vanadium & 1.0 \\
Ferrous & Remainder \\
\hline
\end{tabular}

After the AISI D3 steel samples were prepared as described above (Figure 1), their corrosion behaviour in a $3.5 \% \mathrm{NaCl}$ medium was then examined. For the investigation, abridged labels were used for the AISI D3 steel sample qualifications (Table 2). Thus, the following discussion will be made easier by referring to these codes.

\subsection{Electrochemical measurements}

The electrochemical impedance spectroscopy (EIS) measurements were performed using a Reference 600 Gamry Potentiostat/Galvanostat/ZRA (M/S Gamry Instruments, USA). Before EIS measurement, each sample was immersed in the corrosion cell and allowed to stabilise for $2 \mathrm{~h}$. The EIS studies were performed by imposing a sinusoidal voltage of $10 \mathrm{mV}$ amplitude as the open circuit potential of the working electrode. The frequency was varied between $100 \mathrm{kHz}$ and $1 \mathrm{mHz}$.

\subsection{Surface morphology studies}

After the EIS measurements, surface analyses of the working electrodes were carried out by scanning electron microscopy (SEM) using the Quanta FEG 250 (FEI) model equipped with an energy-dispersive X-ray spectroscopy (EDS) probe.

\section{Results}

\subsection{Electrochemical Impedance Spectroscopy (EIS)}

The corrosion behaviour (in the $3.5 \% \mathrm{NaCl}$ medium) of the AISI D3 steel samples prepared with different pretreatments was investigated by means of EIS conducted at room temperature. The Nyquist, Bode and phase angle plots of the steel alloy are shown in Figures 2 and 3.

As shown in Figure 2, the impedance diagrams take the form of depressed semicircles, indicating charge transfer and diffusion processes. Similar depressed semicircles were

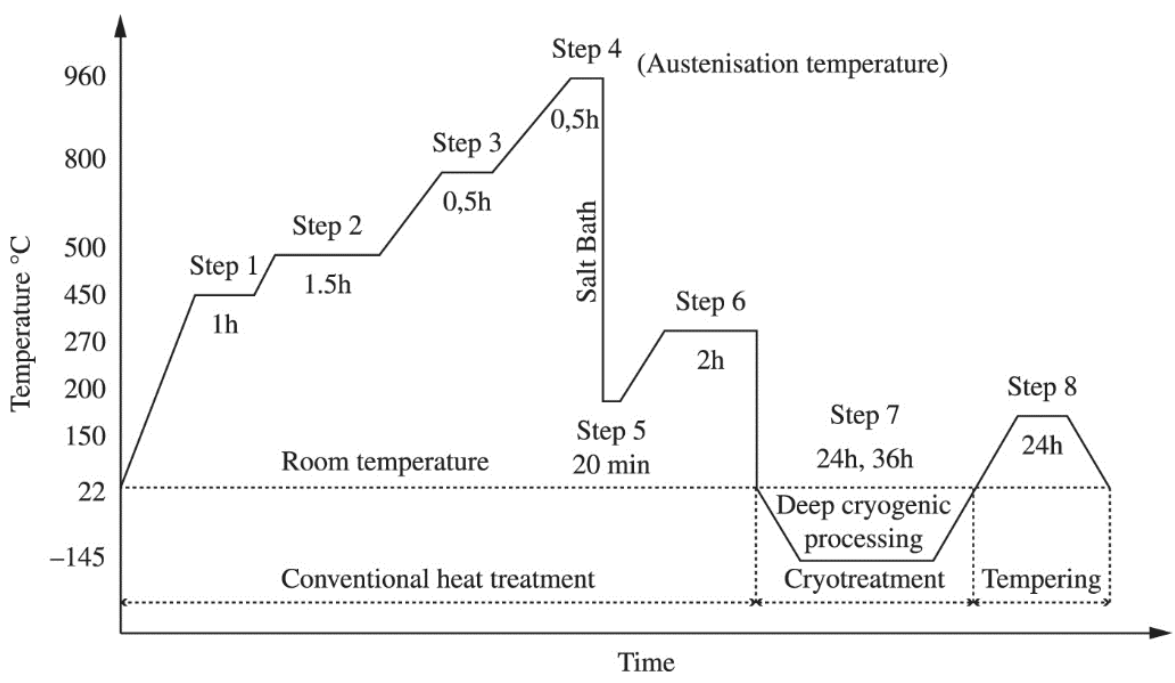

Figure 1. A schematic presentation of the heat treatment schedule consisting of the hardening, deep cryogenic treatment and tempering cycles of the samples. 
obtained with a single time constant, due to the surface heterogeneity of the corrosion product covering the surface at random sites ${ }^{11-14}$. The corresponding Bode plots are shown in Figure 3a. All these findings demonstrate that the investigated AISI D3 steel alloy samples exhibited similar corrosion mechanisms in the $3.5 \% \mathrm{NaCl}$ solution.

The Nyquist plots, analysed with the ZSimpwin 3.10 programme, provide accurate information about the

Table 2. Investigated AISI D3 steel sample codes and qualifications.

\begin{tabular}{|c|c|}
\hline $\begin{array}{c}\text { Sample } \\
\text { (AISI D3) Code }\end{array}$ & Qualifications \\
\hline Q & Without pre-treatment \\
\hline $\mathrm{QH}$ & Heat treatment \\
\hline QH24cry & Heat treatment $+24 \mathrm{~h}$ cryogenic treatment \\
\hline QH36cry & Heat treatment $+36 \mathrm{~h}$ cryogenic treatment \\
\hline QH36cry2temp & $\begin{array}{l}\text { Heat treatment }+36 \mathrm{~h} \text { cryogenic treatment }+ \\
2 \mathrm{~h} \text { tempered }\end{array}$ \\
\hline
\end{tabular}

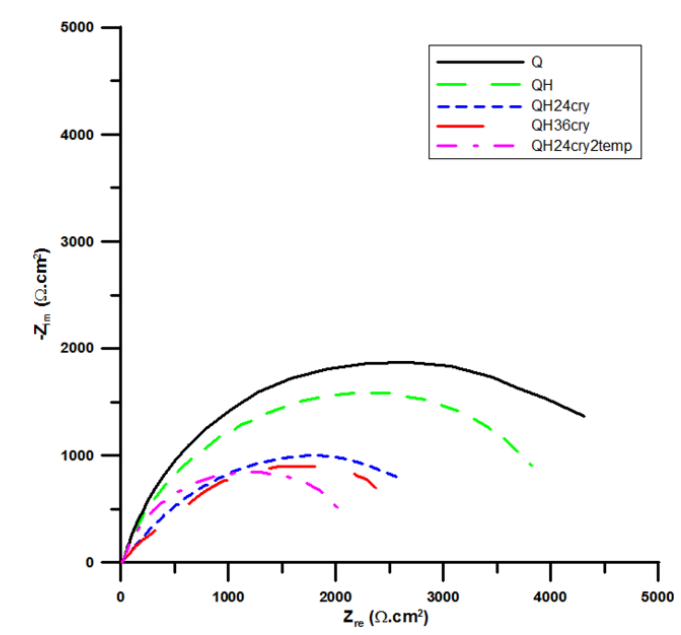

Figure 2. EIS data represented by Nyquist diagrams for different pre-treated AISI D3 steel samples in $3.5 \% \mathrm{NaCl}$ solution.

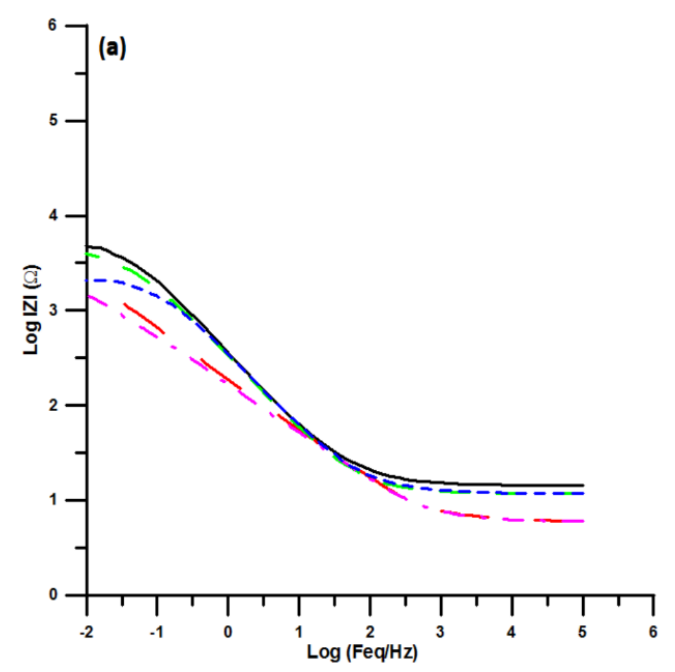

circuit. The measure of goodness-of-fit of the model is the $\chi^{2}$ parameter. During the analysis, $\chi^{2}$ did not exceed $1 \times 10^{-4}$, attesting to a very high fit of the received impedance spectra to the proposed electrical equivalent circuit $^{15}$.

It is clear from previous research and the applied ZSimpwin 3.10 programme that the obtained Nyquist plots can be modelled by a simple Randel's circuit including the charge transfer resistance $\left(R_{\mathrm{ct}}\right)$ parallel with double-layer capacitance $\left(C_{\mathrm{dl}}\right)$ in series with solution resistance $\left(R_{\mathrm{s}}\right)^{16}$. However, Figure 2 shows that the Nyquist plots of AISI D3 steel in $3.5 \% \mathrm{NaCl}$ were not the perfect semicircles expected from the EIS assumption. This difference can be explained by the non-ideal behaviour of the double layer as a capacitor. Therefore, it was necessary to use a constant phase element, $\mathrm{CPE}(Q)$, instead of a double-layer capacity to account for the non-ideal behaviour ${ }^{17}$. Consequently, the $R(Q R)$ circuit model was used to analyse the EIS results ${ }^{18}$. The impedance parameters derived from these investigations are given in Table 3. The impedance of the CPE can be described by Equation 1:

$$
\mathrm{Z}_{\mathrm{CPE}}=\left[\mathrm{Y}_{0}(\mathrm{j} \omega)^{\mathrm{n}}\right]^{-1}
$$

According to this formula, the CPE element may be considered as a double-layer capacitor only when the $n$ values remain close to 1 . The $n$ parameter obtained by means of this study ranged from 0.54 up to 0.80 , thus fulfilling the above requirement. It is noticeable that an increase in $Q$ values is associated with a decrease in $n$ values. Moreover, Table 3 shows that all applied pre-treatment processes caused an increase in their respective $Q$ values.

Figure $3 \mathrm{~b}$ gives phase angle vs. log frequency changes according to the pre-treatment of the AISI D3 steel samples in $3.5 \% \mathrm{NaCl}$ solution. The phase angle values are appropriate for the $R_{\mathrm{ct}}$ changes. The heat, cryogenic and tempering pre-treatment processes decreased the phase angle from 35 to 9 degrees. The calculated $R_{\mathrm{ct}}$ values also decreased with all pre-treatment procedures. It is recognised in previous research that temperature plays an important role in the

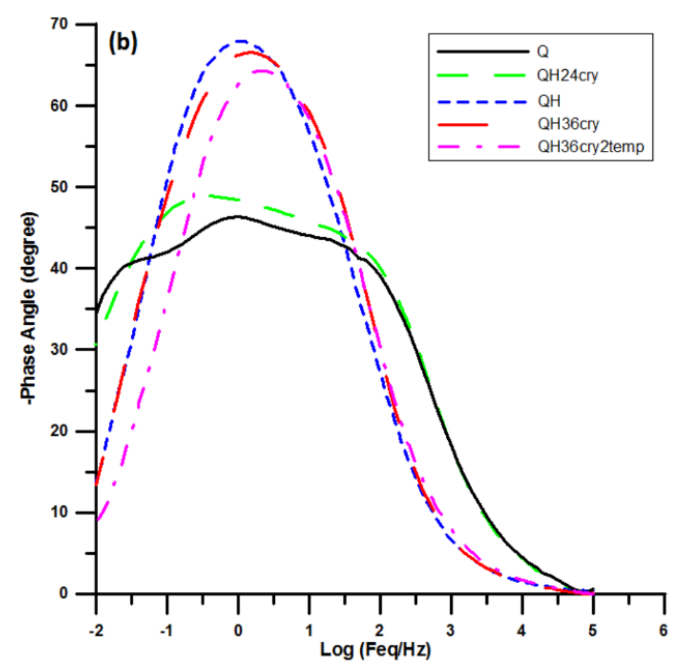

Figure 3. EIS data represented by Bode (a) and phase angle (b) variation vs. log frequency diagrams for different pre-treated AISI D3 steel samples in $3.5 \% \mathrm{NaCl}$ solution 
progress of corrosion reactions and that heat pre-treatment increases the corrosion rate ${ }^{19,20}$. The changes in $Q$ and $n$ values confirmed these findings. The $R_{\mathrm{s}}$ values were between 9 and $14 \Omega$ and nearly constant, as expected, because the solution was the same for all samples.

\subsection{Morphological measurements}

EDS results were obtained from averages of the entire surface areas of the presented SEM images. The SEM micrographs are shown in Figure $4 \mathrm{a}-\mathrm{e}$. Table 4 gives the corresponding EDS spectra of the surface of the AISI D3 steel specimens after conducting electrochemical tests (EIS) on the different pre-treated samples in $3.5 \% \mathrm{NaCl}$ solution. Figure $4 \mathrm{a}$-e reveals that the pre-treatment of AISI D3 steel had a significant effect on the corrosion process. It is clear from Figure 4 that the surface of (a) was damaged less than the others (b-e). The surface of sample (e), with heat treatment $+36 \mathrm{~h}$ cryogenic treatment $+2 \mathrm{~h}$ tempering, was damaged by pitted areas in the typical form of pitting corrosion $^{21,22}$. The surface roughness of samples (d) and (c) seemed to be greater than that in the other SEM images. This study also suggests that initial surface roughness does not have a predominant effect on corrosion resistance. Rather, corrosion resistance is associated with both compressive and residual stresses ${ }^{23}$.

Table 4 shows the general EDS analysis results of the samples and their concentrations ( $w t \%)$. Based on the corresponding EDS results, it can be concluded that all AISI D3 steel samples were corroded in the $3.5 \% \mathrm{NaCl}$ solution. These findings validate the SEM and EIS results. While the concentration of $\mathrm{C}$ was mostly constant, $\mathrm{O}, \mathrm{Cr}$ and $\mathrm{Mn}$ concentrations increased depending on the type of pre-treatment. The reduction in the amount of $\mathrm{Fe}$ and the increase of $\mathrm{Cr}$ has also been reported in previous studies ${ }^{24}$.

Table 3. Impedance parameters for different pre-treated AISI D3 steel samples in 3.5\% $\mathrm{NaCl}$ solution

\begin{tabular}{lccccc}
\hline \multicolumn{1}{c}{ Metal } & $\boldsymbol{R}_{\boldsymbol{s}}(\boldsymbol{\Omega})$ & $\boldsymbol{Q}(\mathbf{C P E})$ & $\boldsymbol{n}(\mathbf{0} \leq \boldsymbol{n} \leq \mathbf{1})$ & $\boldsymbol{R}_{\text {ct }}(\boldsymbol{\Omega})$ & $\boldsymbol{\chi}^{\mathbf{2}}$ \\
\hline Q & 13.72 & $3.69 \mathrm{E}-04$ & 0.80 & 5522 & $1.91 \mathrm{E}-04$ \\
QH & 8.687 & $8.53 \mathrm{E}-04$ & 0.68 & 4518 & $1.99 \mathrm{E}-04$ \\
QH24cry & 9.292 & $1.16 \mathrm{E}-03$ & 0.59 & 3490 & $2.57 \mathrm{E}-05$ \\
QH36cry & 10.34 & $1.56 \mathrm{E}-03$ & 0.55 & 2839 & $3.03 \mathrm{E}-04$ \\
QH36cry2temp & 12.06 & $1.78 \mathrm{E}-03$ & 0.54 & 2354 & $6.80 \mathrm{E}-04$ \\
\hline
\end{tabular}
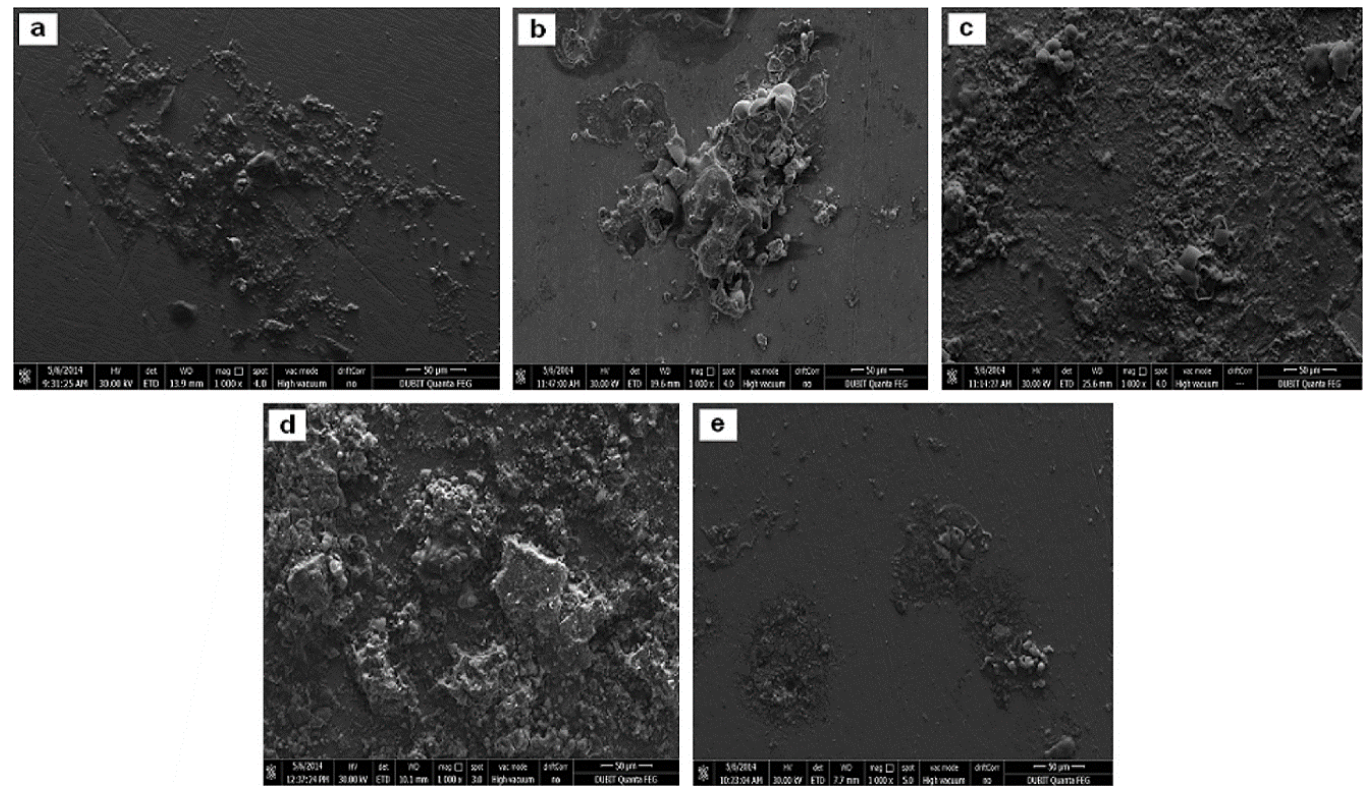

Figure 4. SEM images for different pre-treatment AISI D3 steel samples in 3.5\% $\mathrm{NaCl}$ solution: (a) Q, (b) QH, (c) QH24cry, (d) QH36cry, (e) QH36cry2temp

Table 4. General EDS results of concentration (wt \%) of samples (a-e) in Figure 4.

\begin{tabular}{cccccc}
\hline \multirow{2}{*}{ Element } & \multicolumn{5}{c}{ General EDS results of Figure 4 samples (a-e) conc. (wt\%) } \\
\cline { 2 - 6 } & $\mathbf{Q}$ & QH & QH24cry & QH36cry & QH36cry2temp \\
\hline C & 3.19 & 2.67 & 3.12 & 3.49 & 3.75 \\
O & 25.28 & 31.67 & 35.47 & 41.06 & 45.52 \\
$\mathrm{Cr}$ & 7.47 & 10.01 & 10.45 & 10.92 & 11.7 \\
$\mathrm{Mn}$ & 0.3 & 0.36 & 0.34 & 0.35 & 0.42 \\
$\mathrm{Fe}$ & 63.76 & 55.29 & 50.62 & 44.18 & 38.61 \\
\hline
\end{tabular}




\section{Conclusions}

1. The values of the EIS, SEM and EDS results were in good agreement with each other. The combination of these techniques demonstrated a powerful approach in defining the corrosion process.

2. All investigated samples were corroded in $3.5 \%$ $\mathrm{NaCl}$. Furthermore, the corrosion resistance of these samples can be ranked as follows: $\mathrm{Q}>\mathrm{QH}>\mathrm{QH} 24$ cry $>$ QH36cry > QH36cry2temp.

3. In contrast to the other samples, pits occurred on the surface of the sample of QH36cry2temp pre-treated

\section{References}

1. Mohan Lal D, Renganarayanan S and Kalanidhi A. Cryogenic treatment to augment wear resistance of tool and die steels. Cryogenics. 2001; 41(3):149-155. http://dx.doi.org/10.1016/ S0011-2275(01)00065-0.

2. Singh J, Singh LP and Kaushik A. Enhancing wear resistance of En45 spring steel using cryogenic treatment. Friction and Wear Research. 2013; 1:22-27.

3. Collins DN. Deep cryogenic treatment of tool steels: a review. Heat Treatment of Metals. 1996; 2:40-42.

4. Firouzdor V, Nejati E and Khomamizadeh F. Effect of deep cryogenic treatment on wear resistance and tool life of M2 HSS drill. Journal of Materials Processing Technology. 2008; 206(13):467-472. http://dx.doi.org/10.1016/j.jmatprotec.2007.12.072.

5. Gill SS, Singh J, Singh R and Singh H. Metallurgical principles of cryogenically treated tool steels-a review on the current state of science. International Journal of Advanced Manufacturing Technology. 2011; 54(1-4):59-82. http://dx.doi.org/10.1007/ s00170-010-2935-5.

6. Arslan Y, Uygur I and Jazdzewska A. The effect of cryogenic treatment on microstructure and mechanical response of AISI D3 tool steel punches. Journal of Manufacturing Science and Engineering. 2015; 137(3):034501-034506. http://dx.doi. org/10.1115/1.4029567.

7. Baldissera P and Delprete C. Deep cryogenic treatment of AISI 302 stainless steel: part II - fatigue and corrosion. Materials \& Design. 2010; 31(10):4731-4737. http://dx.doi.org/10.1016/j. matdes.2010.05.015.

8. Wang W, Srinivasan V, Siva S, Albert B, Lal M and Alfantazi A. Corrosion behavior of deep cryogenically treated AISI 420 and AISI 52100 steel. Corrosion Science. 2014; 70(7):708-720. http://dx.doi.org/10.5006/1150.

9. Akhbarizadeh A, Amini K and Javadpour S. Effects of applying an external magnetic field during the deep cryogenic heat treatment on the corrosion resistance and wear behaviour of 1.2080 tool steel. Materials \& Design. 2012; 41:114-123. http:// dx.doi.org/10.1016/j.matdes.2012.03.045.

10. Briant CL and Ritter AM. The effect of gold work on the sensitization of 304 stainless steel. Scripta Metallurgica. 1979; 13(3):177-181. http://dx.doi.org/10.1016/0036-9748(79)90288-6.

11. Morad MS. An electrochemical study on the inhibiting action of some organic phosphonium compounds on the corrosion of mild steel in aerated acid solutions. Corrosion Science. 2000; 42(8):1307-1326. http://dx.doi.org/10.1016/S0010938X(99)00138-9.
AISI D3 steel in $3.5 \% \mathrm{NaCl}$, indicating that the pretreatment procedure had changed the microstructure of the alloy.

4. The use of cryogenic treatment is steadily gaining acceptance as a process for improving the mechanical behaviour of steels. However, as it is well known that corrosion is an electrochemical process, the data obtained here may not be valid for this orientation. Despite the relevant results presented in this study, more detailed knowledge of the process mechanisms under investigation may be provided by utilising DEIS, AES, XPS, Tofu-SIMS and cross-sectional TEM in future studies.

12. Gunasekaran $G$ and Chauhan LR. Eco friendly inhibitor for corrosion inhibition of mild steel in phosphoric acid medium. Electrochimica Acta. 2004; 49(25):4387-4395. http://dx.doi. org/10.1016/j.electacta.2004.04.030.

13. Alagta A, Felhösi I, Telegdi J, Bertoti I and Kalman E. Effect of metal ions on corrosion inhibition of pimeloyl-1,5-dihydroxamic acid for steel in neutral solution. Corrosion Science. 2007; 49(6):2754-2766. http://dx.doi.org/10.1016/j.corsci.2006.11.008.

14. Yadav M, Kumar S and Behera D. Inhibition effect of substituted thiadiazoles on corrosion activity of N80 steel in $\mathrm{HCl}$ solution. Journal of Metallurgy. 2013; 2013:1-14. http:// dx.doi.org/10.1155/2013/256403.

15. Gerengi H, Darowicki K, Slepski P, Bereket G and Ryl J. Investigation effect of benzotriazole on the corrosion of brassMM55 alloy in artificial seawater by dynamic EIS. Journal of Solid State Electrochemistry. 2010; 14(5):897-902. http:// dx.doi.org/10.1007/s10008-009-0923-1.

16. Ashassi-Sorkhabi H, Shaabani B and Seifzadeh D. Corrosion inhibition of mild steel by some Schiff base compounds in hydrochloric acid. Applied Surface Science. 2005; 239(2):154164. http://dx.doi.org/10.1016/j.apsusc.2004.05.143.

17. Ashassi-Sorkhabi H, Seifzadeh D and Hosseini MGEN. EIS and polarization studies to evaluate the inhibition effect of 3H-phenothiazin-3-one, 7-dimethylamin on mild steel corrosion in $1 \mathrm{M} \mathrm{HCl}$ solution. Corrosion Science. 2008; 50(12):33633370. http://dx.doi.org/10.1016/j.corsci.2008.09.022.

18. Gerengi H and Sahin HI. Schinopsis lorentzii extract as a green corrosion inhibitor for low carbon steel in $1 \mathrm{M} \mathrm{HCl}$ solution. Industrial \& Engineering Chemistry Research. 2012; 51(2):780787. http://dx.doi.org/10.1021/ie201776q.

19. BenSalah M, Sabot R, Triki E, Dhouibi L, Refait P and Jeannin M. Passivity of Sanicro28 (UNS N-08028) stainless steel in polluted phosphoric acid at different temperatures studied by electrochemical impedance spectroscopy and Mott-Schottky analysis. Corrosion Science. 2014; 86:61-70. http://dx.doi. org/10.1016/j.corsci.2014.04.056.

20. Jindal R, Raja VS, Gibson MA, Styles MJ, Bastow TJ and Hutchinson CR. Effect of annealing below the crystallization temperature on the corrosion behaviour of $\mathrm{Al}-\mathrm{Ni}-\mathrm{Y}$ metallic glasses. Corrosion Science. 2014; 84:54-65. http://dx.doi. org/10.1016/j.corsci.2014.03.015.

21. Srisuwan N, Ochoa N, Pébère N and Tribollet B. Variation of carbon steel corrosion rate with flow conditions in the presence of an inhibitive formulation. Corrosion Science. 2008; 50(5):12451250. http://dx.doi.org/10.1016/j.corsci.2008.01.029. 
22. Lalvani SB and Zhang G. The corrosion of carbon steel in a chloride environment due to periodic voltage modulation: part II. Corrosion Science. 1995; 37(10):1583-1598. http://dx.doi. org/10.1016/0010-938X(95)00056-P.

23. Trdan U, Ocaña JL and Grum J. Surface modification of aluminium alloys with laser shock processing. Journal of
Mechanical Engineering. 2011; 57(05):385-393. http://dx.doi. org/10.5545/sv-jme.2010.119.

24. May JE, Souza CAC, Nascente PAP, Soares P, Lepienski CM and Kuri SE. Effect of thermal aging conditions on the corrosion properties and hardness of a duplex stainless steel. Materials Research. 2010; 13(4):431-436. http://dx.doi.org/10.1590/ S1516-14392010000400003. 